\title{
Pseudo-binary phase diagram for Zr-based in situ $\beta$ phase composites
}

\author{
S.Y. Lee ${ }^{\text {a) }}$ \\ Department of Materials Science and Engineering, Iowa State University, Ames, Iowa 50011 \\ C.P. Kim \\ Department of Materials Science, California Institute of Technology, Pasadena, California 91125 \\ J.D. Almer and U. Lienert \\ Advanced Photon Source, Argonne National Laboratory, Argonne, Illinois 60439 \\ E. Ustundag \\ Department of Materials Science and Engineering, Iowa State University, Ames, Iowa 50011 \\ W.L. Johnson \\ Department of Materials Science, California Institute of Technology, Pasadena, California 91125
}

(Received 17 June 2006; accepted 31 October 2006)

The pseudo-binary (quasi-equilibrium) phase diagram for Zr-based bulk metallic glasses with crystalline in situ precipitates ( $\beta$ phase) has been constructed from high-temperature phase information and chemical composition analysis. The phase evolution was detected in situ by high-energy synchrotron x-ray diffraction followed by Rietveld analysis of the data for volume fraction estimation. The phase diagram delineates phase fields and allows the control of phase fractions. Combined with related previous work by the authors, this diagram offers a unique opportunity to control both the morphology and volume of the dendritic $\beta$ phase precipitates to enhance the properties of the composites.

\section{INTRODUCTION}

Bulk metallic glasses (BMGs) are attractive structural materials due to their unique mechanical properties such as high elastic strain (about 2\%) and high strength (around $2 \mathrm{GPa}){ }^{1-4}$ However, most BMGs experience sudden failure during unconstrained loading at room temperature, which weakens their potential for loadbearing applications. This lack of ductility in BMGs has been addressed by the development of particulate, wire, and in situ composites with considerable improvement of toughness. ${ }^{5-10}$ Among these, the most promising are the in situ composites in which the second phase develops via chemical portioning during the cooling process. The first in situ BMG composite was developed by Kim et al. in 1999 and is called the " $\beta$ phase composite" because the body-centered cubic (bcc) crystalline precipitate is reminiscent of the $\beta$ allotrope of both $\mathrm{Zr}$ and Ti. ${ }^{11-13}$ The overall composition of the composite is $\mathrm{Zr}_{56.2} \mathrm{Ti}_{13.8} \mathrm{Nb}_{5.0} \mathrm{Cu}_{6.9} \mathrm{Ni}_{5.6} \mathrm{Be}_{12.5}$, while the compositions of the amorphous matrix and the $\beta$ phase are

\footnotetext{
a) Address all correspondence to this author.

e-mail: sylee@iastate.edu

DOI: 10.1557/JMR.2007.0066
}

$\mathrm{Zr}_{44.7} \mathrm{Ti}_{12.2} \mathrm{Nb}_{2.7} \mathrm{Cu}_{10.5} \mathrm{Ni}_{9.1} \mathrm{Be}_{20.8}$ and $\mathrm{Zr}_{71.0} \mathrm{Ti}_{16.3^{-}}$ $\mathrm{Nb}_{10.0} \mathrm{Cu}_{1.8} \mathrm{Ni}_{0.9}$, respectively. ${ }^{14}$ As this composite was discovered while searching for new Zr-based BMG alloys, its matrix composition is very similar to that of Vitreloy $1\left(\mathrm{Zr}_{41.2} \mathrm{Ti}_{13.8} \mathrm{Cu}_{12.5} \mathrm{Ni}_{10.0} \mathrm{Be}_{22.5}\right)$, one of the most successful BMG alloys.

Recent efforts have been devoted to the improvement of the $\beta$ phase composite's performance resulting in a new composition of $\mathrm{Zr}_{56.2} \mathrm{Ti}_{11.3} \mathrm{Nb}_{7.5} \mathrm{Cu}_{6.9} \mathrm{Ni}_{5.6} \mathrm{Be}_{12.5}$. The new composite exhibits increased $\Delta T$ (i.e., the difference between crystallization temperature $T_{\mathrm{x}}$ and glass transition temperature $T_{\mathrm{g}}$ ), which improves stability, and has higher toughness compared to the first $\beta$ phase composite. The present study used the new composite.

The $\beta$ phase BMG composites offer a unique opportunity to control their mechanical properties by manipulating their microstructure, namely the volume fraction, morphology, and size of the precipitates. To develop processing routines that will yield desired microstructures, a phase diagram with composition and temperature information is needed. While the ternary phase diagram of this BMG system was known for room temperature (Fig. 1), ${ }^{15}$ no information existed for higher temperatures, especially about the evolution of the $\beta$ phase during cooling. The present study successfully monitored 


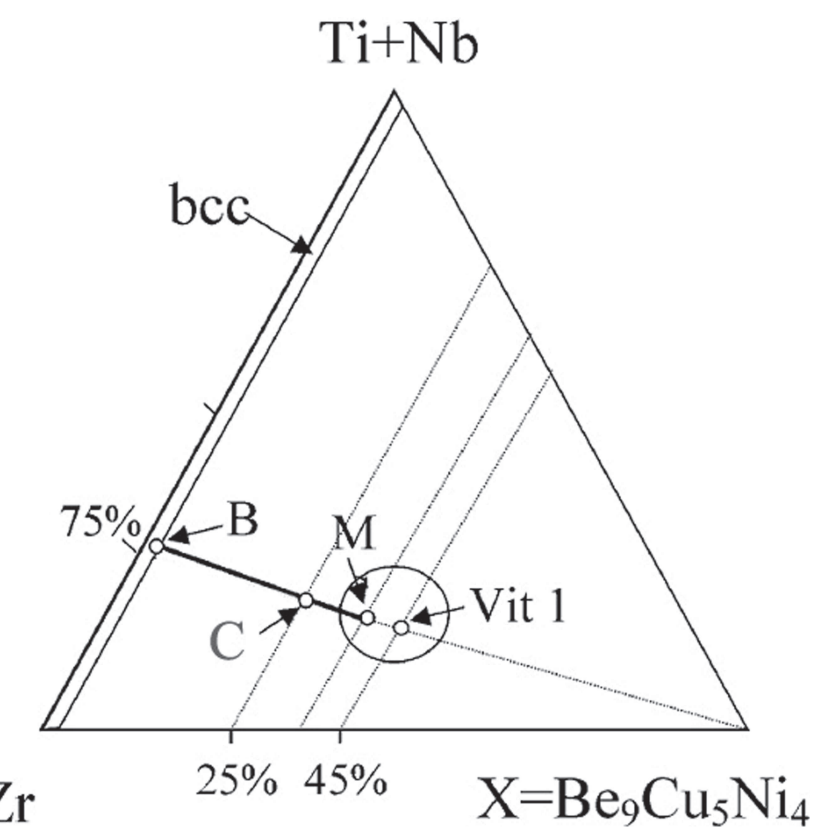

FIG. 1. Vitreloy 1 and in situ $\beta$ phase composite ternary phase diagram at room temperature. ${ }^{15} \mathrm{~B}$ stands for the monolithic $\beta$ phase, $\mathrm{C}$ represents the in situ $\beta$ phase composite, and $M$ is the amorphous matrix inside the composite. The circle around Vitreloy 1 is the glass forming area without the presence of $\mathrm{Nb}$. The ratio between $\mathrm{Zr}$ and $\left(\mathrm{Ti}_{y} \mathrm{Nb}_{1-y}\right)$ is fixed at $75 / 25$, while the content of $\mathrm{Nb}$ could vary.

phase evolution throughout the whole temperature range of composite processing and yielded valuable information to construct a processing map for these in situ BMG composites.

\section{EXPERIMENTAL PROCEDURE}

$\mathrm{Zr}$ based in situ $\beta$ phase BMG composite specimens were prepared by alloying high-purity $(>99.8 \%)$ metallic elements by plasma arc melting in a Ti-gettered argon atmosphere on a water-cooled $\mathrm{Cu}$ plate. Dog-boneshaped tensile samples (thickness: $1.5 \mathrm{~mm}$, length: $30 \mathrm{~mm}$, gauge length: $13 \mathrm{~mm}$, gauge width: $2.0 \mathrm{~mm}$, deviation angle: $10^{\circ}$ ) were machined from the cast ingots.

The samples were examined with x-ray diffraction (XRD) $\left(\mathrm{Cu} \mathrm{K}_{\alpha}\right.$ radiation) and field emission scanning electron microscopy (FE SEM; LEO 1550 VP, Carl Zeiss MicroImaging, Inc., Thornwood, NY) for phase identification at room temperature. A typical microstructure is shown in Fig. 2. The chemical compositions of each phase were measured by an electron microprobe analyzer (JEOL JXA-73, Peabody, MA) with $\mathrm{Zr}, \mathrm{Ti}, \mathrm{Nb}, \mathrm{Cu}$, and $\mathrm{Ni}$ as elemental standards, whereas the Be content was calculated by difference.

In situ phase evolution studies were conducted at beamline 1-ID-C of the advanced photon source (APS). A high-energy ( $80.7 \mathrm{keV}$, wavelength, $\lambda=0.1536 \AA$ ) synchrotron X-ray beam (size: $100 \times 100 \mu \mathrm{m})$ was used in the transmission mode. The data were collected by an area detector (Mar345 digital image plate, $345 \mathrm{~mm}$ in

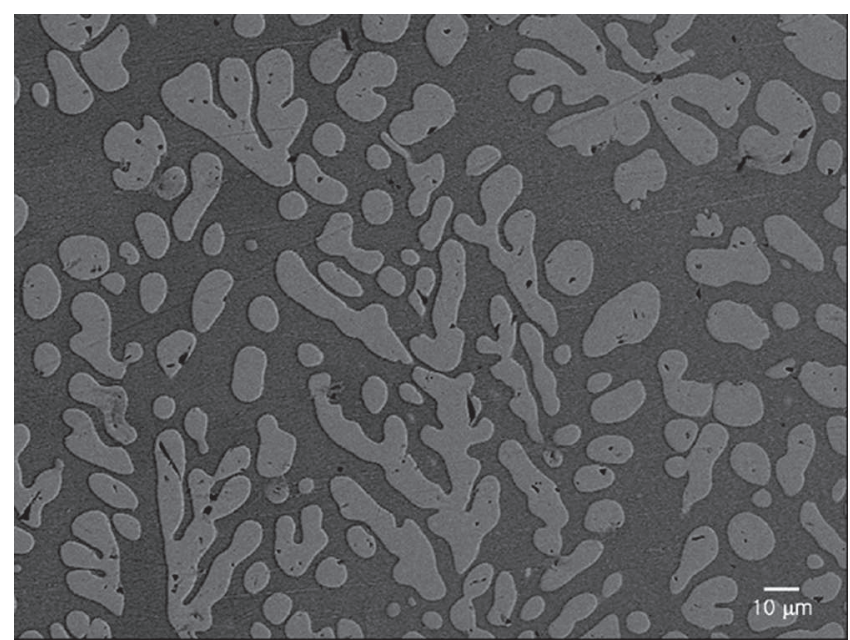

FIG. 2. Backscattered SEM image of an in situ $\beta$ phase/BMG composite. The dark area represents the amorphous matrix while the bright area shows the bcc crystalline $\beta$ phase. ${ }^{19}$

diameter, $150 \mu \mathrm{m}$ pixel size) (Mar USA, Inc., Evanston, IL). The sample was sealed in a quartz tube to prevent oxidation at high temperature, and an infrared (IR) furnace supplied heat at rate of about $50{ }^{\circ} \mathrm{C} / \mathrm{min}$. X-ray exposures took less than $15 \mathrm{~s}$, but detector readout lasted over $1 \mathrm{~min}$, resulting in an overall temporal resolution of approximately $2 \mathrm{~min}$. The sample rested on an alumina rod inside the furnace, and part of this alumina was used as an internal standard to calibrate the diffraction data and to account for sample displacement during heating/ cooling. The Debye rings obtained on the detector were integrated over the full $360^{\circ}$ azimuth angle (for enhanced counting statistics) to yield one-dimensional diffraction patterns for subsequent analysis. This integration can be justified by the isotropic phase evolution expected during heating/cooling.

Rietveld full pattern analysis was performed on the integrated data to match the crystalline peaks with the $\operatorname{Im} \overline{3} m$ body-centered cubic (bcc) space group (lattice constant $\sim 3.5 \AA$ ). ${ }^{16,17}$ The amorphous background was fitted with the background function No. 1 in General Structure Analysis System (GSAS), resulting in good quality fits of $\chi^{2} \sim 0.42$ and a fitting residual (difference between experimental data and crystallographic model) of about 5\% (Fig. 3). Prior to analysis, the diffraction pattern of the empty quartz tube was subtracted from all data to cancel background contributions.

To estimate the volume fraction of the $\beta$ phase, the external standard method was used. ${ }^{18}$ Here, the integrated peak intensity of a given $\beta$ phase reflection is given by

$$
\frac{I_{\beta}}{I_{\beta-\text { ref }}}=\frac{c_{\beta}\left[c_{\beta-\text { ref }}\left(\mu_{\beta}-\mu_{\mathrm{BMG}}\right)+\mu_{\mathrm{BMG}}\right]}{c_{\beta \text {-ref }}\left[c_{\beta}\left(\mu_{\beta}-\mu_{\mathrm{BMG}}\right)+\mu_{\mathrm{BMG}}\right]},
$$

where $c_{\beta}$ is the unknown volume fraction of the $\beta$ phase while $c_{\beta \text {-ref }}$ is that of the reference (or external standard), and the $\mu$ represents the linear absorption coefficient of 


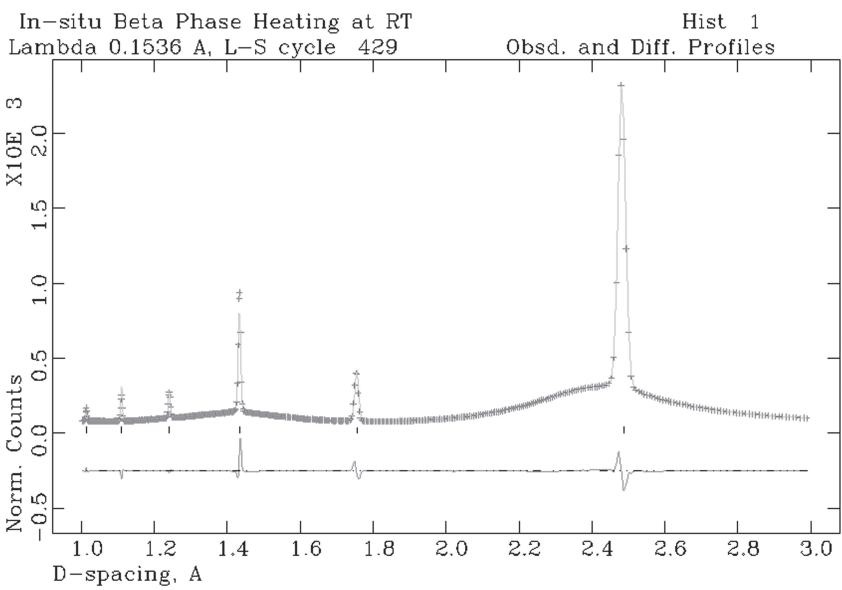

FIG. 3. Rietveld-refined synchrotron XRD pattern of a composite at room temperature. The tick marks indicate reflections from the bcc $\beta$ phase ( $\sim 40 \mathrm{vol} \%)$. The wavy background is largely due to the amorphous matrix ( $\sim 60 \mathrm{vol} \%)$. The bottom curve is the difference between the data (crosses) and the refined crystallographic model (solid line).

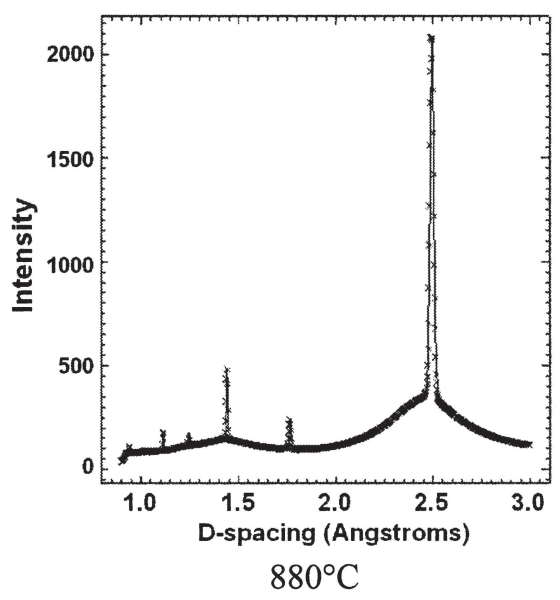

(a) Liquid: $65 \%, \beta$ Phase: $35 \%$

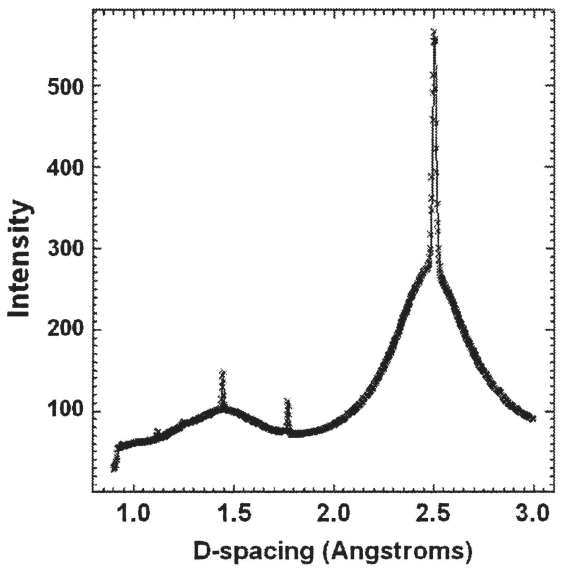

$1030^{\circ} \mathrm{C}$

(c) Liquid: $82 \%, \beta$ Phase: $18 \%$ the corresponding phases. The external standard was taken to be a monolithic $\beta$ phase specimen at room temperature (where $c_{\beta \text {-ref }}=1.0$ ). Diffraction data from the room-temperature version of the composite (with a known $\beta$ phase volume fraction of $c_{\beta}=0.40$ ) were also used in the calculation together with the stoichiometry of each phase. Note that in this method the contributions of the instrument (wavelength, incident intensity, etc.) and the material (structure factor, multiplicity, etc.) to peak intensity are cancelled. This analysis also requires the following assumptions: (i) the $\beta$ phase remains unchanged in terms of chemical composition and structure all the way to its melting point, and (ii) the contribution of the Debye-Waller (or temperature) factor is neglected. The results described below suggest that these assumptions are reasonable for the purpose of phase diagram construction.

\section{RESULTS AND DISCUSSION}

The first step for the construction of the quasiequilibrium phase diagram is to determine the volume

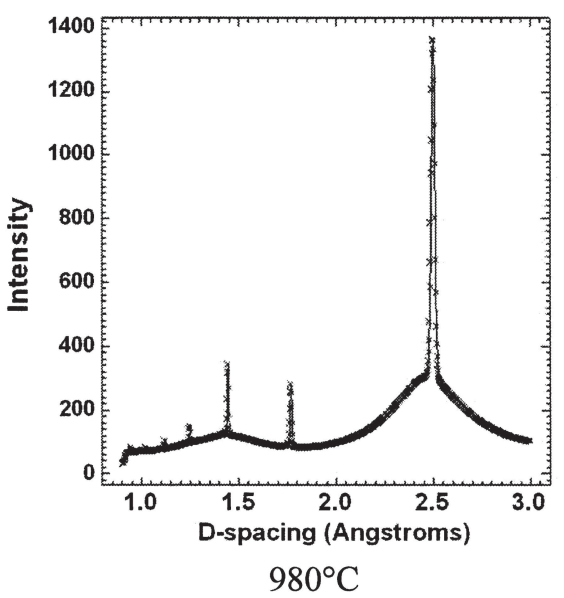

(b) Liquid: $\mathbf{7 4 \%}, \beta$ Phase: $\mathbf{2 6 \%}$

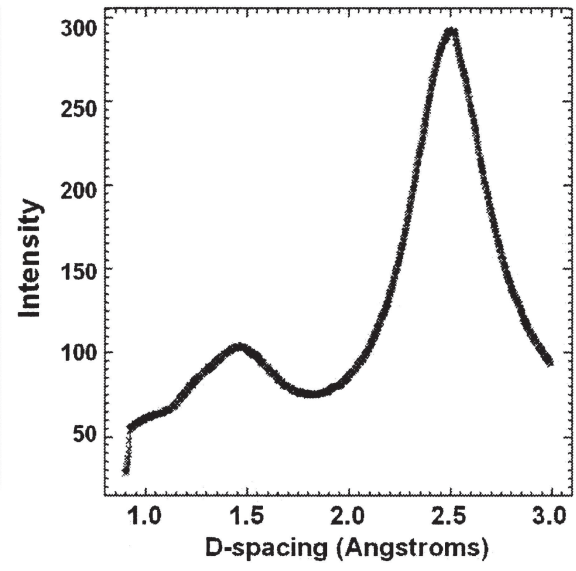

$1150^{\circ} \mathrm{C}$

(d) Liquid: $100 \%, \beta$ Phase: $0 \%$

FIG. 4. Synchrotron XRD data as a function of temperature used in quantifying phase (volume) fractions. The areas under the crystalline peaks and the amorphous background were calculated through peak integration. 


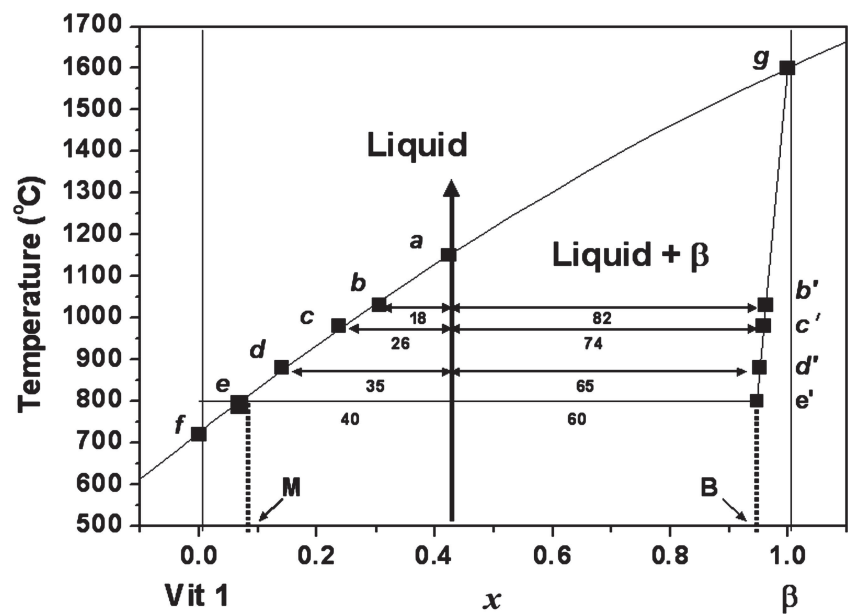

FIG. 5. Quasi-equilibrium phase diagram construction for in situ $\beta$ phase composites. A constant heating rate of $50{ }^{\circ} \mathrm{C} / \mathrm{min}$ has been used. The lower axis designates the fraction of the $\beta$ phase with Vitreloy 1 , $\left(\mathrm{Zr}_{75} \mathrm{Ti}_{25}\right)_{55}\left[\mathrm{Be}_{50}\left(\mathrm{Cu}_{55} \mathrm{Ni}_{45}\right)_{50}\right]_{45}$, and the monolithic $\beta$ phase, $\mathrm{Zr}_{75} \mathrm{Ti}_{25}$ as binary axes. $\mathrm{M}\left(\mathrm{Zr}_{42.2} \mathrm{Ti}_{9.4} \mathrm{Nb}_{3.2} \mathrm{Cu}_{13.7} \mathrm{Ni}_{10.7} \mathrm{Be}_{20.8}\right.$ or $x=$ $0.076)$ and $\mathrm{B}\left(\mathrm{Zr}_{71.1} \mathrm{Ti}_{13.1} \mathrm{Nb}_{13.4} \mathrm{Cu}_{1.6} \mathrm{Ni}_{0.8}\right.$ or $\left.x=0.947\right)$ represent the amorphous matrix and the $\beta$ phase inside the composite, respectively. The vertical arrow at $x=0.424$ marks the composite $\left(\mathrm{Zr}_{75} \mathrm{Ti}_{15} \mathrm{Nb}_{10}\right)_{75}\left[\mathrm{Be}_{50}\left(\mathrm{Cu}_{55} \mathrm{Ni}_{45}\right)_{50}\right]_{25}$ subjected to the heat treatment in Fig. 4. The numbers at each horizontal line are the phase volume fractions from Fig. 4 used in the construction of the quasi-equilibrium phase diagram via the lever rule. Further details are presented in the text.

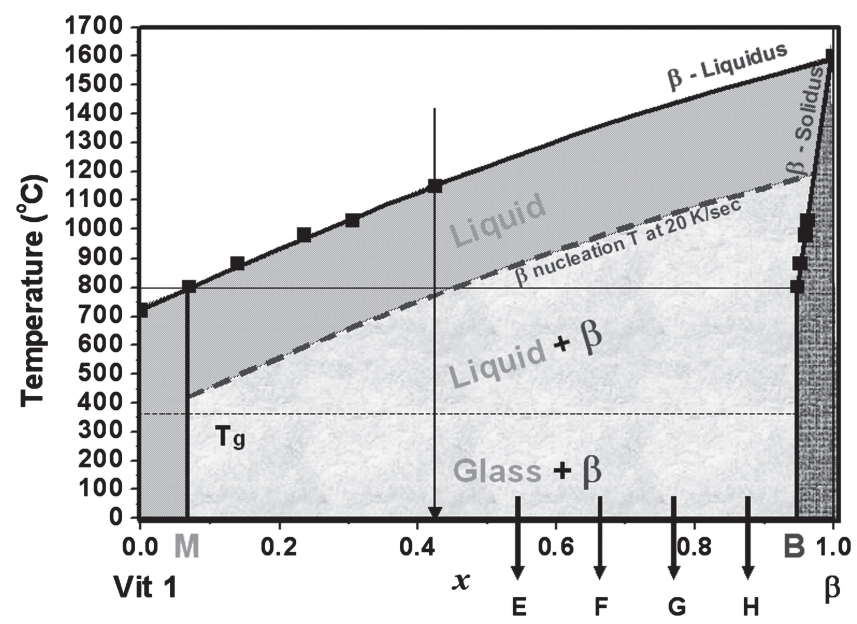

FIG. 6. Processing map (quasi-equilibrium pseudo-binary phase diagram) for in situ $\beta$ phase composites during a cooling experiment. The horizontal axis $x$ is explained in Fig. 5. The $\beta$ phase nucleation curve was obtained from electrostatic levitation (ESL) analysis. ${ }^{21}$ The glass transition temperature $T_{\mathrm{g}}$ of the matrix in the $\beta$ phase composite is close to that of Vitreloy $1\left(\sim 350{ }^{\circ} \mathrm{C}\right) .{ }^{15}$ The composites with compositions marked $\mathrm{E}-\mathrm{H}$ were processed and studied to determine their phase fractions (see Fig. 7) to confirm the phase diagram.

fraction of each phase. The term "quasi" is used because glass formation itself is a kinetic process. On the other hand, in the case of the $\beta$ phase composites, processing conditions allow the construction of a phase diagram that quantifies phase evolution as a function of temperature and composition. For instance, the cooling rates used $(\sim 15 \mathrm{~K} / \mathrm{s})$ are faster than the critical cooling rate of BMG formation $(\sim 1 \mathrm{~K} / \mathrm{s}$ for Vitreloy 1 , which is close to the composition of the amorphous matrix in the composites), ${ }^{19}$ yet the cooling is slow enough to allow the precipitation and growth of the $\beta$ phase, yielding phase fractions that obey the lever rule. The details of this procedure are described below.

Figure 4 shows how the $\beta$ phase melting proceeds as temperature increases. The volume fraction data obtained from Rietveld analysis of the synchrotron XRD patterns were used (together with the lever rule) to construct the quasi-equilibrium phase diagram, as shown in Fig. 5. Here, Vitreloy 1, $\left(\mathrm{Zr}_{75} \mathrm{Ti}_{25}\right)_{55}\left[\mathrm{Be}_{50}\left(\mathrm{Cu}_{55} \mathrm{Ni}_{45}\right)_{50}\right]_{45}$, and monolithic $\beta$ phase, $\mathrm{Zr}_{75} \mathrm{Ti}_{25}$, are selected as binary axes, and the in situ composite, $\left(\mathrm{Zr}_{75} \mathrm{Ti}_{15} \mathrm{Nb}_{10}\right)_{75}\left[\mathrm{Be}_{50^{-}}\right.$ $\left.\left(\mathrm{Cu}_{55} \mathrm{Ni}_{45}\right)_{50}\right]_{25}$, is marked with an arrow at $x=0.424$, according to the lever rule from each solubility limit, based on the fact that the amorphous matrix occupies $60 \mathrm{vol} \%$ and the $\beta$ phase takes up the remaining 40 vol\%. ${ }^{19} \mathrm{Nb}$ has been known to be a $\beta$ phase stabilizer and could be added at the expense of Ti without forming new phases. The direction of the arrow in Fig. 5 means that data were collected during a heating experiment. As the Vitreloy 1 and monolithic $\beta$ phase allow a certain level of solubility of each other (this does not mean Vitreloy 1 is soluble in the $\beta$ phase, but the components of Vitreloy 1 are), the actual amorphous and crystalline phase compositions inside the composite turn out to be $\mathrm{M}\left(\mathrm{Zr}_{42.2} \mathrm{Ti}_{9.4} \mathrm{Nb}_{3.2} \mathrm{Cu}_{13.7} \mathrm{Ni}_{10.7} \mathrm{Be}_{20.8}\right)$ and $\mathrm{B}\left(\mathrm{Zr}_{71.1^{-}}\right.$$\mathrm{Ti}_{13.1} \mathrm{Nb}_{13.4} \mathrm{Cu}_{1.6} \mathrm{Ni}_{0.8}$ ), determined by electron microprobe analysis. $\mathrm{M}$ sits on $x=0.076$ based on a $\mathrm{Be}$ content of $20.8 \%$ as the amorphous matrix of the composite, compared with $22.5 \% \mathrm{Be}$ in Vitreloy 1 . The $\beta$ phase (B) occupies $x=0.947$ from $[(97.6-55.0) /$ $(100-55)=0.947]$, according to the $\mathrm{Zr}_{75}\left(\mathrm{Ti}_{y} \mathrm{Nb}_{1-y}\right)_{25}$ overall content of $97.6 \%$. \{Note that Vitreloy 1 , $\left(\mathrm{Zr}_{75} \mathrm{Ti}_{25}\right)_{55}\left[\mathrm{Be}_{50}\left(\mathrm{Cu}_{55} \mathrm{Ni}_{45}\right)_{50}\right]_{45}$, has $55 \%$ of $\mathrm{Zr}_{75^{-}}$ $\left(\mathrm{Ti}_{y} \mathrm{Nb}_{1-y}\right)_{25}$, while the monolithic $\beta$ phase has $100 \%$ $\mathrm{Zr}_{75}\left(\mathrm{Ti}_{y} \mathrm{Nb}_{1-y}\right)_{25}$.

The melting temperatures of Vitreloy $1\left(720^{\circ} \mathrm{C}\right.$-point $f$ in Fig. 5 $)^{1}$ and the monolithic $\beta$ phase $\left(1600^{\circ} \mathrm{C}\right.$-point $g$ in Fig. 5 $)^{20}$ were deduced from literature. These two points anchor the $\beta$ phase liquidus. The point $e^{\prime}$ was determined by extending the composition of B upward. The data points, $b^{\prime}, c^{\prime}$, and $d^{\prime}$ were interpolated from $e^{\prime}$ and $g$. Because the composite chemical compositions are known ( $\mathrm{M}$ and $\mathrm{B}$ ) and the $\beta$ phase solidus line is fixed $\left(e^{\prime}-g\right)$, the $\beta$ phase liquidus line could be calculated. As the glass volume fraction changes to $65 \%, 74 \%, 82 \%$, and $100 \%$ at $880,980,1030$, and $1150{ }^{\circ} \mathrm{C}$, respectively, data points $a, b, c$, and $d$ were calculated according to the lever rule. The smooth variation along the $\beta$ phase liquidus line suggests the results are consistent.

While the diagram in Fig. 5 offers useful data about 


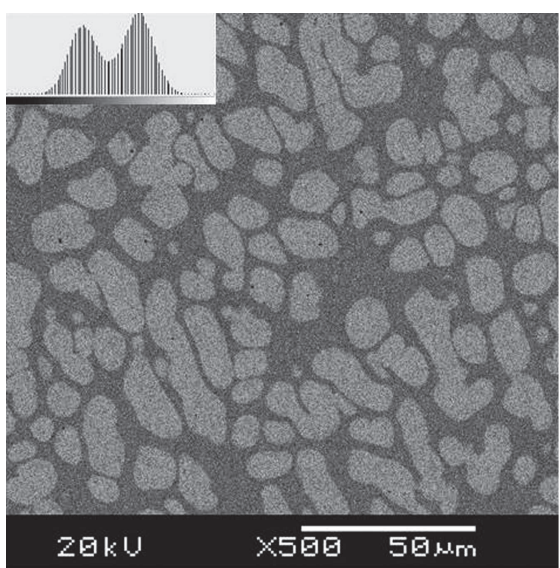

(a) $\mathrm{E}(x=0.55)$

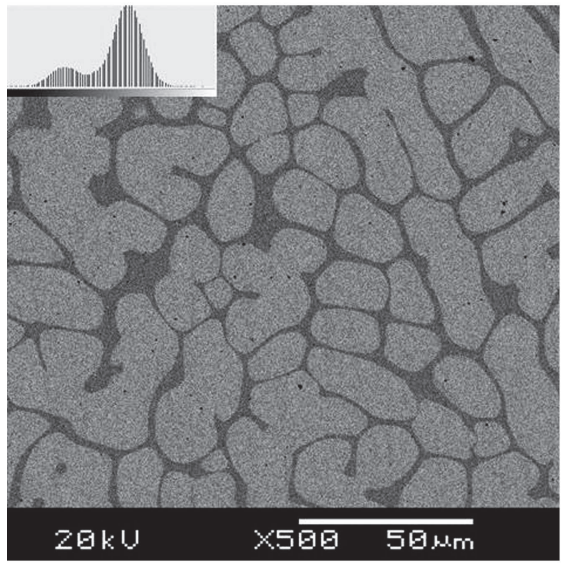

(c) $\mathrm{G}(x=0.77)$

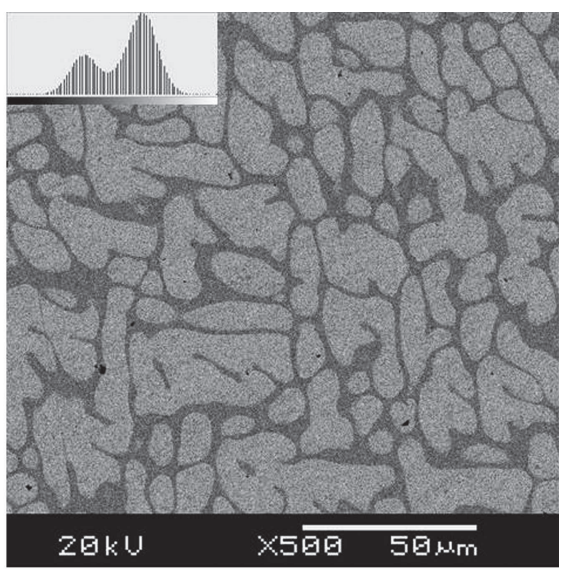

(b) $\mathrm{F}(x=0.66)$

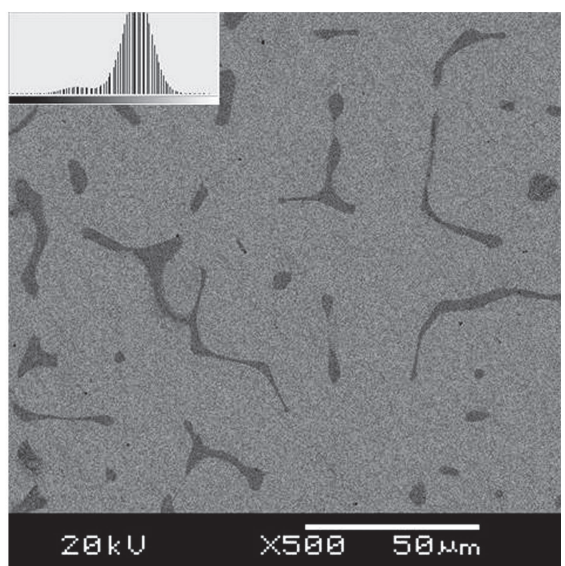

(d) $\mathrm{H}(x=0.88)$

FIG. 7. Backscattered SEM images of the composites marked in Fig. 6. The light regions designate the $\beta$ phase, and the dark areas are the amorphous matrix. The insets on the upper left corner show the intensity distributions used in estimating the fractions of each phase.

TABLE I. Chemical compositions of the composites shown in Figs. 6 and 7. The third column lists the volume fractions of the $\beta$ phase estimated from the quasi-equilibrium phase diagram, and the last column is the corresponding values measured by the image analysis of Fig. 7 . The two sets of data are closely matched.

\begin{tabular}{|c|c|c|c|}
\hline $\begin{array}{c}\text { Composite label } \\
\text { (Figs. } 6 \text { and 7) }\end{array}$ & Chemical composition & Estimated vol $\%$ of $\beta$ phase & Measured vol $\%$ of $\beta$ phase \\
\hline $\mathrm{E}$ & $\left(\mathrm{Zr}_{75} \mathrm{Ti}_{15} \mathrm{Nb}_{10}\right)_{80}\left[\mathrm{Be}_{50}\left(\mathrm{Cu}_{55} \mathrm{Ni}_{45}\right)_{50}\right]_{20}$ & 55 & $57 \pm 3$ \\
\hline $\mathrm{F}$ & $\left(\mathrm{Zr}_{75} \mathrm{Ti}_{15} \mathrm{Nb}_{10}\right)_{85}\left[\mathrm{Be}_{50}\left(\mathrm{Cu}_{55} \mathrm{Ni}_{45}\right)_{50}\right]_{15}$ & 68 & $67 \pm 3$ \\
\hline G & $\left(\mathrm{Zr}_{75} \mathrm{Ti}_{15} \mathrm{Nb}_{10}\right)_{90}\left[\mathrm{Be}_{50}\left(\mathrm{Cu}_{55} \mathrm{Ni}_{45}\right)_{50}\right]_{10}$ & 80 & $81 \pm 2$ \\
\hline $\mathrm{H}$ & $\left(\mathrm{Zr}_{75} \mathrm{Ti}_{15} \mathrm{Nb}_{10}\right)_{95}\left[\mathrm{Be}_{50}\left(\mathrm{Cu}_{55} \mathrm{Ni}_{45}\right)_{50}\right]_{5}$ & 93 & $93 \pm 2$ \\
\hline
\end{tabular}

phase stability limits, additional information is needed to construct a full processing map. Because glass formation and $\beta$ phase precipitation are highly sensitive to processing conditions, especially the cooling rate, kinetics information is required. Mukherjee reported that the $\beta$ phase dendrites start to nucleate homogeneously at $780{ }^{\circ} \mathrm{C}$ with about $400{ }^{\circ} \mathrm{C}$ undercooling if the cooling rate is $20 \mathrm{~K} / \mathrm{s}^{21,22}$ It is also worth noting that the glass transition temperature of both Vitreloy 1 and the amorphous matrix of the composites is about $350{ }^{\circ} \mathrm{C} .{ }^{19}$ Adding this kinetics information to Fig. 5 results in a full processing map for in situ $\beta$ phase composites, as shown in Fig. 6.
To confirm this processing map, four different composites were made and studied by SEM imaging: $\mathrm{E}(x=0.55), \mathrm{F}(x=0.66), \mathrm{G}(x=0.77)$, and $\mathrm{H}(x=0.88)$. Figure 7 shows the SEM results, and the estimated volume fractions from the phase diagram are in good agreement with measured volume fractions of the $\beta$ phase. For example, for the composite $G$, the phase diagram predicted $80 \mathrm{vol} \% \beta$ phase, while the measured value was 81 vol\% $( \pm 2 \mathrm{vol} \%)$. The remaining data are exhibited in Table I, and all show good agreement between the phase diagram predictions and experimental values. 
The preceding discussion demonstrated how one can use a processing map such as Fig. 6 to control the fraction of the $\beta$ phase precipitates in these composites. Another important aspect of microstructural control involves the dendrite size. This was investigated in detail previously by Lee, ${ }^{19}$ who showed that, by a judicious choice of processing conditions, it is possible to vary the dendrite size between 0.4 and $14 \mu \mathrm{m}$. As Figs. 5 and 6 demonstrate, the $\beta$ phase volume fraction will be governed by the lever rule between compositions $\mathrm{M}$ and $\mathrm{B}$. However, at a given point of temperature and composition, one can suppress dendrite growth with enhanced nucleation rate. For example, if the material is held around $600-700{ }^{\circ} \mathrm{C}$ at the composition of $x=0.28$ in Fig. 6, it is highly possible to obtain a finer dendritic composite. Additional research is underway to develop more detailed processing conditions that add further kinetics information to Fig. 6, especially for dendrite size control, but the present processing map can be considered a good starting point.

\section{SUMMARY}

One of the most promising BMG composites (with dendritic crystalline precipitates-the $\beta$ phase) was investigated to construct its pseudo-binary (quasi-equilibrium) phase diagram. Chemical analysis was combined with in situ XRD data as a function of temperature to determine the stability limits of the $\beta$ phase, and the lever rule was used to quantify its volume fraction. The diagram was complemented with kinetics data that include the cooling rate effects yielding a processing map for $\beta$ phase composites. This map then becomes a powerful tool to control the microstructure of the composites (i.e., $\beta$ phase dendrite size, morphology and volume fraction) so that their mechanical properties can be enhanced.

\section{ACKNOWLEDGMENTS}

The authors would like to thank Jin-Yoo Suh at Caltech for assisting sample preparation as well as Minha Lee at Ames National Laboratory for help with SEM observation.

\section{REFERENCES}

1. A. Peker: Formation and characterization of bulk metallic glasses, Ph.D. Thesis, California Institute of Technology, Pasadena, CA (1994), p. 57.

2. R.D. Conner, A.J. Rosakis, W.L. Johnson, and D.M. Owen: Fracture toughness determination for a beryllium-bearing bulk metallic glass. Scripta Mater. 37, 1373 (1997).

3. C.J. Gilbert, R.O. Ritchie, and W.L. Johnson: Fracture toughness and fatigue-crack propagation in a $\mathrm{Zr}-\mathrm{Ti}-\mathrm{Ni}-\mathrm{Cu}-\mathrm{Be}$ bulk metallic glass. Appl. Phvs. Lett. 71, 476 (1997).
4. W.L. Johnson: Fundamental aspects of bulk metallic glass formation in multicomponent alloys, in Metastable, Mechanically Alloyed and Nanocrystalline Materials, Pts. 1 and 2, Vol. 225 (1996), p. 35.

5. H. Choi-Yim, R. Busch, U. Koster, and W.L. Johnson: Synthesis and characterization of particulate reinforced $\mathrm{Zr}_{57} \mathrm{Nb}_{5} \mathrm{Al}_{10} \mathrm{Cu}_{15.4^{-}}$ $\mathrm{Ni}_{12.6}$ bulk metallic glass composites. Acta Mater. 47, 2455 (1999).

6. H. Choi-Yim, J. Schroers, and W.L. Johnson: Microstructures and mechanical properties of tungsten wire/particle reinforced $\mathrm{Zr}_{57} \mathrm{Nb}_{5} \mathrm{Al}_{10} \mathrm{Cu}_{15.4} \mathrm{Ni}_{12.6}$ metallic glass matrix composites. Appl. Phys. Lett. 80, 1906 (2002).

7. B. Clausen, S.Y. Lee, E. Ustundag, C.C. Aydiner, R.D. Conner, and M.A.M. Bourke: Compressive yielding of tungsten fiber reinforced bulk metallic glass composites. Scripta Mater. 49, 123 (2003).

8. R.D. Conner, R.B. Dandliker, and W.L. Johnson: Mechanical properties of tungsten and steel fiber reinforced $\mathrm{Zr}_{41.25} \mathrm{Ti}_{13.75^{-}}$ $\mathrm{Cu}_{12.5} \mathrm{Ni}_{10} \mathrm{Be}_{22.5}$ metallic glass matrix composites. Acta Mater. 46, 6089 (1998).

9. C.C. Hays, C.P. Kim, and W.L. Johnson: Microstructure controlled shear band pattern formation and enhanced plasticity of bulk metallic glasses containing in situ formed ductile phase dendrite dispersions. Phys. Rev. Lett. 84, 2901 (2000).

10. S.Y. Lee, B. Clausen, E. Ustundag, H. Choi-Yim, C.C. Aydiner, and M.A.M. Bourke: Compressive behavior of wire reinforced bulk metallic glass matrix composites. Mater. Sci. Eng. A 399. 128 (2005).

11. B. Clausen, S.Y. Lee, E. Ustundag, C.P. Kim, D.W. Brown, and M.A.M. Bourke: Deformation of in-situ-reinforced bulk metallic glass matrix composites. Mater. Sci. Forum 404-407, 553 (2002).

12. C.C. Hays, C.P. Kim, and W.L. Johnson: Improved mechanical behavior of bulk metallic glasses containing in situ formed ductile phase dendrite dispersions. Mater. Sci. Eng., A 304, 650 (2001).

13. F. Szuecs, C.P. Kim, and W.L. Johnson: Mechanical properties of $\mathrm{Zr}_{56.2} \mathrm{Ti}_{13.8} \mathrm{Nb}_{5.0} \mathrm{Cu}_{6.9} \mathrm{Ni}_{5.6} \mathrm{Be}_{12.5}$ ductile phase reinforced bulk metallic glass composite. Acta Mater. 49, 1507 (2001).

14. B. Clausen, S.Y. Lee, E. Ustundag, C.P. Kim, D.W. Brown, and M.A.M. Bourke: Compressive deformation of in situ formed bulk metallic glass composites. Scripta Mater. 54, 343 (2006).

15. C.P. Kim: Ductile phase reinforced bulk metallic glass composites formed by chemical partitioning, Ph.D. thesis, California Institute of Technology, Pasadena, CA (2001), p. 48.

16. A.C. Larson and R.B. Von Dreele: GSAS-General Structure Analysis System, LAUR 86-748 (Los Alamos National Laboratory, Los Alamos, NM, 1986)

17. H.M. Rietveld: Line profiles of neutron powder-diffraction peaks for structure refinement. Acta Crystallogr. 22, 151 (1967).

18. B.D. Cullity: Elements of X-ray Diffraction (Addison-Wesley, Reading, MA, 1978), p. 407.

19. S.Y. Lee: Deformation mechanisms of bulk metallic glass matrix composites, Ph.D. Thesis, California Institute of Technology, Pasadena, CA (2005), p. 97.

20. Titanium-zirconium, in The Handbook of Binary phase diagrams, Vol. 5, edited by W.G. Moffat (General Electric Company, Corporate Research and Development, New York, 1976).

21. S. Mukherjee: Study of crystallization behavior, kinetics and thermodynamics of bulk metallic glasses using noncontact electrostatic levitation technique, Ph.D. thesis, California Institute of Technology, Pasadena, CA (2005), p. 117.

22. Y.J. Kim, R. Busch, W.L. Johnson, A.J. Rulison, and W.K. Rhim: Experimental determination of a time-temperature-transformation diagram of the undercooled $\mathrm{Zr}_{41.2} \mathrm{Ti}_{13.8} \mathrm{Cu}_{12.5} \mathrm{Ni}_{10.0} \mathrm{Be}_{22.5}$ alloy using the containerless electrostatic levitation processing technique. Appl. Phvs. Lett. 68, 1057 (1996). 